\title{
Carbon dioxide insufflation is associated with increased serrated polyp detection rate when compared to room air insufflation during screening colonoscopy
}

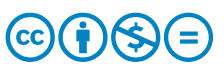

\author{
Authors \\ Institutions \\ 1 Division of Gastroenterology, University of Florida, \\ Gainesville, Florida, United States \\ 2 Department of Health Outcomes and Policy, University \\ of Florida, Gainesville, Florida, United States \\ 3 Department of Medicine, University of Florida, \\ Gainesville, Florida, United States
}

Michael Riverso', Yaseen B. Perbtani ${ }^{1}$, Jonathan J. D. Shuster ${ }^{2}$, Joydeep Chakraborty ${ }^{3}$, Tony S. Brar ${ }^{3}$, Mitali Agarwal ${ }^{3}$, Han Zhang ${ }^{3}$, Anand Gupte', Shailendra S. Chauhan', Christopher E. Forsmark¹, Peter V. Draganov ${ }^{1}$, Dennis Yang1

submitted 21.1.2017

accepted after revision 16.6.2017

\author{
Bibliography \\ DOI https://doi.org/10.1055/s-0043-116382 | \\ Endoscopy International Open 2017; 05: E905-E912 \\ (c) Georg Thieme Verlag KG Stuttgart · New York \\ ISSN 2364-3722
}

Corresponding author

Dennis Yang, MD, Division of Gastroenterology, University of Florida, 1329 SW 16th Street, Suite 5251, Gainesville, FL 32608

Fax: $+1-352-627-9002$

Dennis.Yang@medicine.ufl.edu

\section{ABSTRACT}

Background and study aims Sessile serrated adenomas (SSA) and traditional serrated adenomas (TSA) have been increasingly recognized as precursors of colorectal cancer. The aim of this study was to compare the effect of carbon dioxide insufflation $\left(\mathrm{CO}_{2} \mathrm{l}\right)$ vs. room air insufflation $(\mathrm{AI})$ on serrated polyp detection rate (SPDR) and to identify factors associated with SPDR.

Patients and methods Single-center retrospective cohort study of 2083 screening colonoscopies performed with Al (November 2011 through January 2013) or $\mathrm{CO}_{2} \mathrm{I}$ (February 2013 to June 2015). Data on demographics, procedure characteristics and histology results were obtained from a prospectively maintained endoscopy database and chart review. SPDR was defined as proportion of colonoscopies in which $\geq 1$ SSA, TSA or hyperplastic polyp (HP) $\geq 10 \mathrm{~mm}$ in the right colon was detected. Multi-variate analysis (MVA) was performed to identify predictors of SPDR.

Results A total of 131 histologically confirmed serrated polyps (129 SSA, 2 TSA and $0 \mathrm{HP} \geq 10 \mathrm{~mm}$ ) were detected. SPDR was higher with $\mathrm{CO}_{2} \mathrm{I}$ vs. $\mathrm{Al}(4.8 \%$ vs. $1.4 \% ; P<$ $0.0001)$. On MVA, $\mathrm{CO}_{2} \mathrm{I}$ was associated with higher SPDR when compared to Al (OR: 9.52; $95 \% \mathrm{Cl}$ : 3.05-30.3). Both higher body mass index (OR 1.05; $95 \% \mathrm{Cl}: 1.02-1.09)$ and longer colonoscope withdrawal time (OR 1.11; $95 \% \mathrm{Cl}$ : $1.07-1.16$ ) were also associated with higher SPDR.

Conclusion $\mathrm{CO}_{2} \mathrm{I}$ is associated with higher SPDR when compared to Al during screening colonoscopy. While the mechanism remains unknown, we speculate that the favorable gas characteristics of $\mathrm{CO}_{2}$ compared to room air results in improved polyp detection by optimizing bowel insufflation. These findings suggest an additional reason to prefer the use of $\mathrm{CO}_{2} \mathrm{I}$ over Al during colonoscopy.

\section{Introduction}

Colorectal cancer (CRC) is the second leading cause of cancer death in the United States. Screening colonoscopy is a well-recognized and advocated intervention for CRC death prevention $[1,2]$. The efficacy of this strategy is invariably dependent on the quality of the procedure in terms of detecting and effectively removing precancerous lesions. Hence, the adenoma detection rate (ADR) has been emphasized as an important quali- ty indicator for colonoscopy given the supporting evidence on ADR and its impact on CRC [3].

Serrated polyps, such as sessile serrated adenomas (SSA) and traditional serrated adenomas (TSP) are distinguished from hyperplastic polyps (HP) given their increased recognition as precursors of CRC [4-6]. Indeed, a recent large populationbased case-control study have shown that serrated polyps may potentially confer a similar if not higher risk for CRC when compared to conventional adenomas [7]. SSAs are characterized by their usual low flat profile and the presence of a yellow mucus 
cap overlying the lesion [8-10]. These morphological features may partially account for their diagnostic challenge during screening colonoscopy. Consequently, missed proximal SSAs are thought to be an important cause for interval cancers in the right colon and underscores the importance of developing quality measures intended to improve their detection [11 - 13].

The true prevalence of serrated polyps remains largely unknown, with studies reporting varying serrated polyp detection rates ranging from $1 \%$ to $22 \%$ [14-17]. Both patient- and endoscopist-related factors have been associated with serrated polyp detection rate (SPDR). Intuitively, adequate luminal distention during screening colonoscopy should be of utmost importance in the identification of these premalignant lesions. Recently, carbon dioxide insufflation $\left(\mathrm{CO}_{2} \mathrm{I}\right)$ has become increasingly utilized for colonoscopy due to its favorable patientrelated outcomes, such as reduced post-procedural bloating and discomfort when compared to standard room air insufflation (AI) [18]. The recently published ESGE colorectal polypectomy and EMR guideline suggested the use of $\mathrm{CO}_{2}$ I for colonoscopy and polypectomy, and recommended the use of $\mathrm{CO}_{2}$ for colorectal EMR $[19,20]$. However, there is limited data on the impact of $\mathrm{CO}_{2} \mathrm{I}$ on the detection of premalignant lesions during screening colonoscopy. The aims of this study were to compare SPDR in patients undergoing screening colonoscopy with $\mathrm{CO}_{2} \mathrm{I}$ versus $A$ I and to identify factors influencing SPDR in an average CRC risk population.

\section{Patients and methods}

\section{Study design and patient population}

The study was approved by the institutional review board (IRB) of the University of Florida in which a waiver for informed consent was obtained. The prospectively maintained endoscopic database at the University of Florida Health (UF Health) was retrospectively reviewed to search for patients who had undergone a screening colonoscopy between November 2011 and June 2015. Eligible patients included those $\geq 50$ years with an average CRC risk. Patients were excluded if they had a personal or first-degree relative family history of CRC, history of colon polyps, inflammatory bowel disease, gastrointestinal bleeding, history of partial colon resection, incomplete/aborted procedures, and any colonoscopy performed for an indication other than CRC screening. Informed procedural consents were obtained from all patients. Al was used for luminal distention in all procedures performed before January 21, 2013. Following this date, the routine use of $\mathrm{CO}_{2} \mathrm{I}$ was adopted universally for all endoscopic procedures at UF Health.

\section{Colonoscopy procedure}

Screening colonoscopies were performed by 1 of the 20 experienced, board-certified gastroenterologists at the University of Florida. Each endoscopist had an experience of over 1000 colonoscopies. All participating gastroenterology ( $\mathrm{Gl}$ ) trainees (first to third year of fellowship training) were under the direct supervision of one of these endoscopists. The bowel preparation agent most commonly used was 4 liters of polyethylene glycol solution. Bowel preparation quality was rated as excellent, good, fair, or poor based on the Aronchick scale [21]. All procedures were performed under provider or anesthesiologist administered conscious sedation (fentanyl and midazolam) or propofol sedation. Cecal intubation was confirmed by the identification of landmarks (i. e. ileocecal valve and/or appendiceal orifice). Total procedure time (defined as the time interval between scope insertion to removal from the patient) and withdrawal time (defined as the amount of time spent examining the mucosa as the colonoscope is withdrawn from the cecum to the rectum) were prospectively documented in the electronic report by the assisting nurses. High-definition monitors (NDS Radiance SC-WX32-A1511, NDS Radiance G2, or FSN FSL3202 D) were used for all colonoscopies during the study period.

\section{Data collection}

Patient demographics and histopathology of polyps were obtained from chart review. Demographic data included age, gender, body mass index (BMI) and the American Society of Anesthesia (ASA) physical status grade. Polyps were classified according to the revised Vienna criteria and World Health Organization classification system $[22,23]$. Polyp histopathology was divided into adenomatous (classified as tubular, tubulovillous, villous or adenocarcinoma) and serrated (classified as sessile serrated, traditionally serrated or hyperplastic). Dysplasia was defined as either low grade or high grade.

Procedural characteristics were obtained from the prospective maintained report generating database. These included: type of sedation (conscious vs. propofol), grading of bowel preparation, trainee participation, procedural times, cecal intubation, and if polyps were detected and removed. Adverse events were defined as per the American Society of Gastrointestinal Endoscopy (ASGE) established criteria [24] and were identified by reviewing the colonoscopy report and the postprocedural note in the electronic record.

\section{Definitions and study outcomes}

Colonoscopy data were analyzed to calculate the polyp detection rate (PDR) (proportion of colonoscopies in which $\geq 1$ polyp was detected), ADR (proportion of colonoscopies in which $\geq 1$ histologically confirmed adenoma was detected) and the SPDR (proportion of colonoscopies in which $\geq 1$ histologically confirmed SSA, TSA or HP $\geq 10 \mathrm{~mm}$ in the right colon was detected). The right colon was defined as the cecum, ascending colon, transverse colon and splenic flexure whereas the left colon included the descending colon, sigmoid colon and rectum.

The primary aim of this study was to compare the SPDR in patients undergoing screening colonoscopy with $\mathrm{Al}$ versus $\mathrm{CO}_{2}$ I. A secondary aim was to identify variables associated SPDR in our cohort.

\section{Statistical methods}

Baseline characteristics between the two cohorts $\left(\mathrm{Al}\right.$ and $\left.\mathrm{CO}_{2} \mathrm{I}\right)$ were compared by (a) the t-test with the Satterthwaite correction for unequal variances for quantitative variables (age, BMI, 
- Table 1 Baseline characteristics.

\begin{tabular}{|c|c|c|c|c|}
\hline Variable & $\begin{array}{l}\text { Overall } \\
(n=2083)\end{array}$ & $\begin{array}{l}\mathrm{CO}_{2} \mathrm{I} \\
(\mathrm{n}=1449)\end{array}$ & $\begin{array}{l}\text { Al } \\
(n=634)\end{array}$ & $P$ value \\
\hline Age, mean $\pm S D$ (years) & $59 \pm 8.7$ & $59.1 \pm 8.7$ & $58.8 \pm 8.9$ & 0.44 \\
\hline Male, n(\%) & $959(46)$ & $675(46.4)$ & $284(44.8)$ & 0.53 \\
\hline $\mathrm{BMI}$, mean $\pm \mathrm{SD}, \mathrm{kg} / \mathrm{m}^{2}$ & $31.7 \pm 9$ & $31.6 \pm 8.8$ & $32.1 \pm 9.3$ & 0.21 \\
\hline \multicolumn{5}{|l|}{ ASA score } \\
\hline .1 & $74(3.6)$ & $50(3.5)$ & $24(3.8)$ & 0.19 \\
\hline . II & $902(43.3)$ & $619(42.7)$ & $283(44.6)$ & \\
\hline . III & $1022(49)$ & $711(49.1)$ & $311(49.1)$ & \\
\hline. $\mathrm{IV}$ & $85(4.1)$ & $69(4.8)$ & $16(2.5)$ & \\
\hline Trainee involvement, n(\%) & $861(41.3)$ & $550(38)$ & $311(49)$ & $<.0001$ \\
\hline \multicolumn{5}{|l|}{ Quality of bowel preparation } \\
\hline - Excellent & $281(13.5)$ & $180(12.4)$ & $101(15.9)$ & 0.002 \\
\hline - Good & $1210(58.1)$ & $829(57.2)$ & $381(60.1)$ & \\
\hline - Fair & $429(20.6)$ & $319(22.0)$ & $110(17.4)$ & \\
\hline " Poor & $163(7.8)$ & $121(8.4)$ & $42(6.6)$ & \\
\hline Cecal intubation rate, $\mathrm{n}(\%)$ & $2049(98.4)$ & $1421(98.1)$ & $628(99.1)$ & 0.1 \\
\hline Total procedure time, mean \pm SD (minutes) & $20 \pm 9.7$ & $19.6 \pm 9.6$ & $21 \pm 9.9$ & 0.002 \\
\hline Scope withdrawal time, mean \pm SD (minutes) & $9.6 \pm 6.6$ & $9.4 \pm 6.4$ & $10.2 \pm 6.9$ & 0.03 \\
\hline
\end{tabular}

total procedure time, and scope withdrawal time); (b) Pearson's chi-square for binary variables (gender, trainee involvement, cecal intubation rate); and (c) the Wilcoxon test for ordinal variables (ASA score and Bowel preparation grading).

Univariate analysis was conducted by univariate and multiple logistic regression. The odds ratios for quantitative independent variables reflect the ratio of odds, for 2 subjects with 1 with a value 1 unit higher than the other, but otherwise equivalent on other covariates in the model-if any-higher value to lower value. The multivariate model estimates the odds ratio (and compares it to the null value of 1.00) adjusting for all other variables in the model. Significance in the multiple regression model means that the variable has independent significant prognostic value that cannot be accounted for by the other variables in the model. All P-values are 2-sided. SAS (Statistical Analysis Systems) version 9.4 was used in all of the analyses.

\section{Results}

\section{Baseline characteristics}

A total of 2083 screening colonoscopies were performed from November 2011 until June 2015. Overall, mean age was $59 \pm$ 8.7 years and $46 \%$ were men. Of these colonoscopies, 634 (30.4\%) were performed with $\mathrm{Al}$ compared to 1449 (69.6\%) with $\mathrm{CO}_{2} \mathrm{I}$ ( $\triangleright$ Table 1 ). There were no significant differences in age, gender, BMI or ASA grade between the $\mathrm{Al}$ vs. $\mathrm{CO}_{2} \mathrm{I}$ groups.
Both the total procedural and withdrawal time were slightly longer in patients undergoing colonoscopy with $\mathrm{Al}$ vs. $\mathrm{CO}_{2} \mathrm{I}$. Cecal intubation rate was similarly high in both groups $(99.1 \%$ with $\mathrm{Al}$ vs. $98.1 \%$ with $\left.\mathrm{CO}_{2} \mathrm{l} ; P=0.1\right)$. Gl trainees were more commonly involved in colonoscopies with $\mathrm{Al}(49.1 \%)$ vs. $\mathrm{CO}_{2} \mathrm{I}$ (38\%) $(P<0.001)$. In aggregate, quality of the bowel preparation was rated better in patients undergoing colonoscopy with Al vs. $\mathrm{CO}_{2} \mathrm{I}(P=0.002)$.

\section{Polyp characteristics and detection rate}

A total of 1835 polyps were detected in this study, of which 1120 were adenomas, 131 were serrated polyps (129 SSAs, 2 TSAs and $0 \mathrm{HP} \geq 1 \mathrm{~cm}$ in right colon) and $584 \mathrm{HPs}$. The median number of colonoscopies performed per endoscopist was 46 (range: 3-496). The overall PDR was 45\% (range 0-69.2), ADR was $30.9 \%$ (range $0-60)$, and SPDR $3.7 \%(0-12.3)$. The colonoscopy performance characteristics per endoscopist are summarized in $>$ Table 2 .

Detection rates between patients undergoing screening colonoscopy with $\mathrm{Al}$ vs. $\mathrm{CO}_{2} \mathrm{I}$ are shown in $\mathbf{F i g}$. 1. The PDR was significantly higher in the $\mathrm{CO}_{2} \mathrm{l}$ group vs. Al group (46.5\% vs. 41.6\%; $P=0.02)$. Similarly, SPDR was also significantly higher in patients undergoing colonoscopy with $\mathrm{CO}_{2}$ I vs. $\mathrm{Al}$ (4.8\% vs. 1.4 $\% ; p<0.0001)$. There was no statistically significant difference in ADR between the two groups. In aggregate, there were no HPs $\geq 10 \mathrm{~mm}$ detected. Most of the HPs removed (95.3\%) were 
- Table 2 Colonoscopy performance per endoscopist.

\begin{tabular}{|c|c|c|c|c|}
\hline $\begin{array}{l}\text { Endos- } \\
\text { copist }\end{array}$ & $\begin{array}{l}\text { Colonosco- } \\
\text { pies }(n)\end{array}$ & PDR (\%) & ADR (\%) & SPDR (\%) \\
\hline 1 & 3 & 0 & 0 & 0 \\
\hline 2 & 10 & 60 & 60 & 0 \\
\hline 3 & 9 & 66.7 & 55.6 & 0 \\
\hline 4 & 13 & 69.2 & 53.9 & 0 \\
\hline 5 & 86 & 56.7 & 34.9 & 3.5 \\
\hline 6 & 8 & 25 & 0 & 0 \\
\hline 7 & 24 & 50 & 45.8 & 4.2 \\
\hline 8 & 26 & 46.2 & 26.9 & 3.9 \\
\hline 9 & 45 & 44.4 & 35.6 & 0 \\
\hline 10 & 31 & 61.3 & 48.4 & 6.5 \\
\hline 11 & 46 & 39.1 & 23.9 & 0 \\
\hline 12 & 65 & 47.7 & 35.4 & 12.3 \\
\hline 13 & 14 & 35.7 & 28.6 & 0 \\
\hline 14 & 48 & 39.6 & 31.3 & 4.2 \\
\hline 15 & 198 & 38.4 & 28.8 & 3.5 \\
\hline 16 & 317 & 48.3 & 27.4 & 3.2 \\
\hline 17 & 208 & 48.1 & 36.5 & 3.9 \\
\hline 18 & 199 & 43.7 & 34.7 & 3.5 \\
\hline 19 & 237 & 44.7 & 24.1 & 2.5 \\
\hline 20 & 496 & 41.9 & 29.6 & 4.4 \\
\hline Overall & 2083 & 45 & 30.9 & 3.7 \\
\hline \multicolumn{5}{|c|}{$\begin{array}{l}\text { ADR, adenoma detection rate; PDF, polyp detection rate; SPDR, serrated } \\
\text { polyp detection rate }\end{array}$} \\
\hline
\end{tabular}

located in the left colon. There was no statistically difference in the detection rate of HPs in the $\mathrm{CO}_{2} \mathrm{I}$ and $\mathrm{Al}$ groups (16.2\% vs. $13.7 \% ; P=0.17)$.

We also examined whether SPDR varied during different time intervals of the study period. For $\mathrm{Al}$, the SPDR was $1.82 \%$ (11/2011 through 6/2012) and then $0.83 \%$ (7/2012 through $12 / 2012)$. For $\mathrm{CO}_{2} \mathrm{l}$, the SPDR in 6-month intervals was as follows: $4.52 \%$ (2/2013 through 7/2013), 3.6\% (8/2013 through 12/2013), 5.44\% (1/2014 through 6/2014), $4.41 \%$ (7/2014 through $12 / 2014)$, and $5.44 \%$ (1/2015 through 6/2015). There was no statistically significant difference in SPDR between the time intervals evaluated.

\section{Variables associated with SPDR}

Univariate and multiple logistic regression analyses were performed to identify variables associated with SPDR ( $>$ Table 3 ). Patient characteristics such as higher BMI was positively associated with SPDR on both uni (OR 1.04; $95 \% \mathrm{Cl}: 1.02-1.06 ; P=$ 0.0008 ) and multivariate (OR 1.05; $95 \% \mathrm{Cl}: 1.02-1.09 ; P=$ 0.0004 ) analyses. While both scope withdrawal time and total procedure time correlated positively with SPDR on univariate analysis, only scope withdrawal time (OR 1.11; $95 \% \mathrm{Cl}: 1.07$ 1.16; $P<0.0001$ ) was found to positively impact SPDR on multivariate analysis. $\mathrm{CO}_{2} \mathrm{I}$ was associated with a higher SPDR when compared to $\mathrm{Al}$ on both univariate (OR: 3.91; $95 \% \mathrm{Cl}: 1.87-$ 8.20; $P=0.0003$ ) and multivariate analysis (OR: $9.52 ; 95 \% \mathrm{Cl}$ : $3.05-30.3 ; P=0.0001)$. Other covariates, including quality of bowel preparation, trainee involvement, and method of sedation (conscious sedation vs. propofol) were not significantly associated with SPDR.

The type of colonoscope (standard vs. high-definition) was not readily available for all procedures; consequently, this data was not included in the multivariate analysis. Overall, there was no difference in SPDR in the $\mathrm{COI}_{2}$ group based on the type of colonoscope $(4.72 \%$ with standard vs. $4.5 \%$ with high-definition; $P=0.97)$. Similarly, the type of colonoscope did not affect the SPDR in patients undergoing colonoscopy with air insufflation ( $1 \%$ with standard vs. $1.4 \%$ with high-definition; $P=0.77$ ).

\section{Adverse events}

There were no procedural or sedation-related adverse events reported on either the prospective colonoscopy database or on the post-procedural note on chart review. A total of 6 cases were aborted prematurely due to patient discomfort/intolerance. Out of these, 4 cases were in the $\mathrm{Al}$ vs 2 in the $\mathrm{CO}_{2} \mathrm{I}$ group $(P=0.07)$.

\section{Discussion}

The effectiveness of screening colonoscopy at reducing the morbidity and mortality associated with CRC is invariably dependent on the optimal detection and resection of premalignant cancerous lesions. Serrated polyps, particularly sessile serrated adenomas, can be difficult to detect endoscopically and may be in part responsible for the decreased performance of colonoscopy in the right colon and a significant proportion of interval CRCs. In this study, $\mathrm{CO}_{2}$ I during screening colonoscopy was shown to be associated with a higher SPDR when compared to Al. Furthermore, both higher BMI and longer colonoscope withdrawal time positively correlated with SPDR.

$\mathrm{CO}_{2} \mathrm{I}$ has been increasingly advocated as an alternate method for luminal distention to Al. Several studies have reported that $\mathrm{CO}_{2} \mathrm{I}$ compared to $\mathrm{Al}$ is associated with decreased bloating and pain in patients undergoing routine colonoscopy [25-27]. Yet, the available data on the effect of $\mathrm{CO}_{2} \mathrm{I}$ on the detection of precancerous lesions during screening colonoscopy is limited. In this study, we demonstrate that SPDR was significantly higher during screening colonoscopy with $\mathrm{CO}_{2} \mathrm{I}$ vs. $\mathrm{Al}$ (4.8\% vs $1.4 \%$; $P<0.0001)$. The SPDR in this study is congruent to those previously reported, including a multicenter study by Payne et al demonstrating a cumulative SPDR of $2.8 \%$ (range $0-9.8 \%$ ) [28]. Our results indicate that method of insufflation during screening colonoscopy was strongly correlated with SPDR, with $\mathrm{CO}_{2} \mathrm{I}$ associated with almost a ten-fold higher SPDR when compared to $\mathrm{Al}$ (OR 9.52; 95\% Cl: 3.05-30.3; $P<0.0001$ ). We speculate that differences in SPDR between $\mathrm{CO}_{2} \mathrm{I}$ and $\mathrm{Al}$ may be related to their gas characteristics. $\mathrm{CO}_{2}$ is absorbed across 

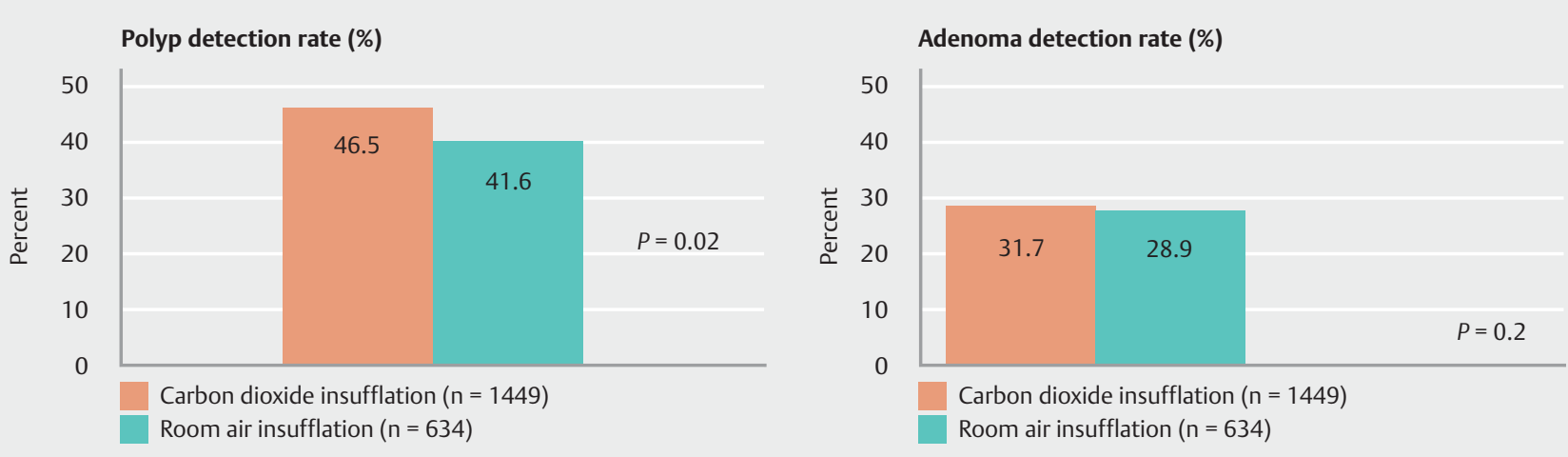

\section{Serrated polyp detection rate (\%)}
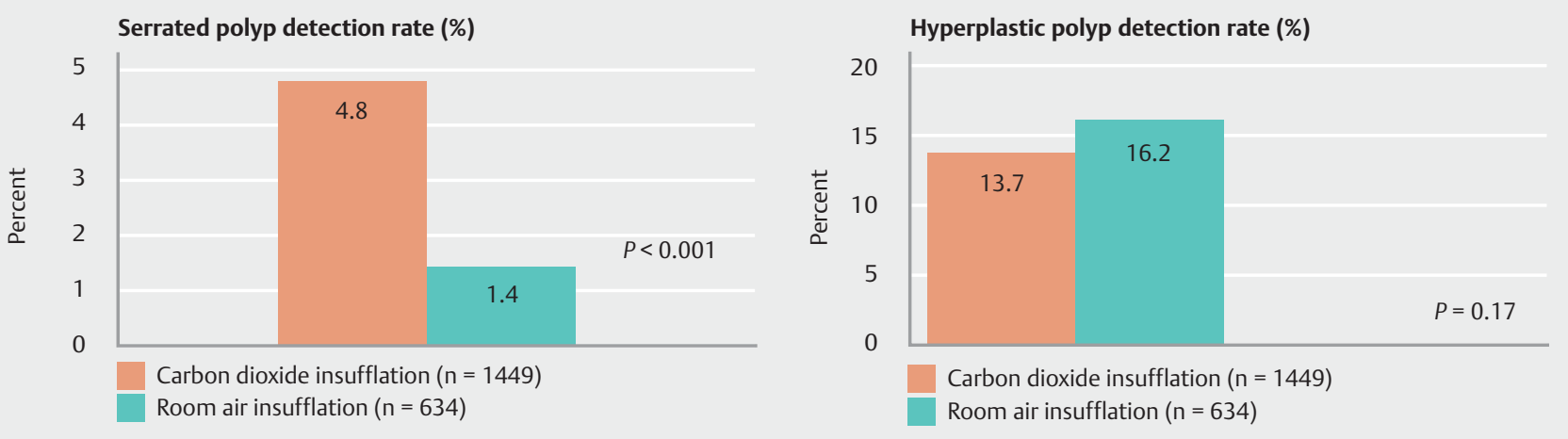

- Fig. 1 Detection rates between patients undergoing screening colonoscopy with $\mathrm{Al}$ vs. $\mathrm{CO}_{2} \mathrm{I}$.

- Table 3 Variables associated with SPDR.

\begin{tabular}{|c|c|c|c|c|}
\hline \multirow[t]{2}{*}{ Clinical variable } & \multicolumn{2}{|l|}{ Univariate analysis } & \multicolumn{2}{|c|}{ Multivariate analysis } \\
\hline & OR $(95 \% \mathrm{Cl})$ & $P$ value & OR $(95 \% \mathrm{Cl})$ & $P$ value \\
\hline Age (years) & $1.0(0.97-1.03)$ & 0.93 & $1.02(0.99-1.05)$ & 0.293 \\
\hline Gender (male vs female) & $0.828(0.52-1.31)$ & 0.42 & $1.23(0.70-2.16)$ & 0.47 \\
\hline $\operatorname{BMI}\left(\mathrm{kg} / \mathrm{m}^{2}\right)$ & $1.04(1.02-1.06)$ & 0.0008 & $1.05(1.02-1.09)$ & 0.0004 \\
\hline ASA score (1 vs 2/3/4) & $2.87(0.39-20.9)$ & 0.30 & $4.03(0.44-36.6)$ & 0.22 \\
\hline Trainee involvement (yes vs no) & $1.26(0.80-1.98)$ & 0.33 & $0.71(0.39-1.30)$ & 0.27 \\
\hline Cecal intubation (yes vs no) & $1.27(0.17-9.41)$ & 0.82 & - & - \\
\hline Scope withdrawal time (per minute) & $1.10(1.07-1.13)$ & $<.0001$ & $1.11(1.07-1.16)$ & $<0.0001$ \\
\hline Total procedure time (per minute) & $1.05(1.03-1.07)$ & $<.0001$ & $1.01(0.98-1.05)$ & 0.59 \\
\hline $\begin{array}{l}\text { Quality of bowel preparation } \\
\text { (Excellent/good vs fair/poor) }\end{array}$ & $1.08(0.65-1.77)$ & 0.77 & $0.70(0.35-1.42)$ & 0.32 \\
\hline Type of scope (high-definition vs standard) & $1.64(0.39-6.83)$ & 0.50 & - & - \\
\hline Type of sedation (conscious vs moderate anesthesia care) & $2.13(0.92-4.95)$ & 0.08 & $1.14(0.38-3.42)$ & 0.82 \\
\hline Method of insufflation $\left(\mathrm{CO}_{2} \mid \mathrm{vs} \mathrm{Al}\right)$ & $3.91(1.87-8.20)$ & 0.0003 & $9.52(3.05-30.3)$ & 0.0001 \\
\hline
\end{tabular}


the intestines approximately 150 times faster than room air which accounts for its favorable profile in terms of patient discomfort and bloating [29,30]. Endoscopists are commonly aware of the deleterious effects associated with room air retention in the colon and thereby gas aspiration is performed regularly during scope withdrawal. Aggressive gas aspiration may adversely collapse the lumen and impede adequate visualization. We theorize that $\mathrm{CO}_{2}$ may have been aspirated less than room air by endoscopists during withdrawal which in turn resulted in better colon insufflation, yet without overly distending the lumen as to miss low-profile lesions. While this potential difference in insufflation did not affect ADR between the two groups, it may have played a larger role in the effective detection of subtle low-profile lesions and plausibly account for the higher SPDR with $\mathrm{CO}_{2} \mathrm{I}$ in this study.

Our study demonstrates that withdrawal time positively correlates with SPDR (OR 1.11; $95 \% \mathrm{Cl}$ : 1.07-1.16; $P<0.0001)$. These results are consistent with those previously reported in the literature. In a prospective study of 1354 colonoscopies, de Wijkerslooth et al examined the impact of patient and endoscopist factors on proximal serrated polyp detection [16]. The authors observed that only withdrawal time was associated with a higher proximal serrated polyp detection rate on multivariate analysis. Similarly, Liang et al also reported a strong association between longer withdrawal time and serrated detection rate in colonoscopies performed by 6 colorectal surgeons [17]. Butterly et al demonstrated that rates of detection of clinically significant serrated polyps reached highest levels with a withdraw time of 8 minutes and continued to remain high at 9 minutes, suggesting that an 8- to 9-minute withdrawal time is ideal for detecting these types of lesions [31]. Variability in withdrawal times may in part account for the discrepant SPDR among endoscopists reported in the literature [14, 15]. In aggregate, our findings further corroborate the importance of withdrawal time as a surrogate marker for the quality of the screening colonoscopy. Future studies are needed to better define what should be considered the optimal withdrawal time to achieve an acceptable SPDR.

Obesity and the metabolic syndrome have been strongly associated with an increased risk for CRC [32]. Indeed, it has been previously estimated that up to two-thirds of CRC may be attributable to modifiable lifestyle risk factors [33]. More recently, Bailie et al reported a systemic review and meta-analysis on lifestyle risk factors for serrated colorectal polyps [34]. The authors included 43 studies of serrated polyp risk associated with 7 different lifestyle factors. In aggregate, tobacco smoking (relative risk ratio (RR) 2.47; $95 \% \mathrm{Cl}: 2.12-2.87$ ), alcohol intake (RR 1.33; $95 \% \mathrm{Cl}: 1.17-1.52$ ) and BMI (RR 1.40; $95 \% \mathrm{Cl}: 1.22-$ 1.61 ) were factors found to significantly increase the risk of serrated polyps. In our study, higher BMI positively correlated with SPDR on both uni- and multi-variate analyses (OR: 1.05; $95 \%$ $\mathrm{Cl}: 1.02-1.09 ; P=0.0004)$. Our results further support the growing evidence on the relationship between $\mathrm{BMI}$ and the risk for serrated polyps. Future research is needed to further investigate the role of BMI in the serrated pathway to carcinogenesis.
This study has several strengths. We performed a comprehensive and detailed assessment of SPDR in 2083 consecutive screening colonoscopies at our institution. Similar to the study by Payne et al [28], SPDR was calculated by the proportion of subjects with at least one histologically proven SSA, TSA or hyperplastic polyp $>10 \mathrm{~mm}$ in the right colon. This definition accounts for the probability of misdiagnosing SSA/TSAs (as large HPs) and excludes clinically insignificant small HPs in the left colon that may cause an overestimation of SPDR. Furthermore, multiple established quality metrics were prospectively collected over a 4-year period and included in our analysis. Patient (age, gender, BMI, quality of bowel preparation), endoscopist (cecal intubation rate, total procedural and withdrawal time, Gl trainee participation) and procedural (type of sedation, type of colonoscope) characteristics were all evaluated for their association with SPDR. Our results demonstrating that both higher BMI and scope withdrawal time positively correlate with SPDR, which is consistent with prior studies. Most importantly, this is the first study suggesting that $\mathrm{CO}_{2} \mathrm{I}$ is associated with a higher SPDR when compared to Al even after adjusting for potential confounding factors. The results from this study may provide the background for future prospective comparative trials evaluating the effect of different methods of luminal distention (i.e. $\mathrm{Al}, \mathrm{CO}_{2} \mathrm{I}$, water immersion) on SPDR during screening colonoscopy.

This study also has some limitations. First, this was a singlecenter study at a tertiary care facility and results may not be generalizable to all ambulatory endoscopic units. Furthermore, this was a retrospective study with its inherent limitations, including baseline differences in gastroenterology trainee involvement, quality of bowel preparation, and procedural times between patients undergoing colonoscopy with $\mathrm{Al}$ vs. $\mathrm{CO}_{2} \mathrm{I}$. Nonetheless, the impact of these variables on SPDR was assessed and adjusted by performing a logistic regression analysis thereby limiting any confounding effect. Second, other factors, including patient position change during colonoscopy or the specific method of bowel prep administration (i.e. split dose vs. day prior) could not be captured in our database and thereby were not included in the analysis. Furthermore, the type of colonoscope (i. e. standard definition vs. high definition) was not readily available for all procedures. On subgroup analysis, there was no difference in SPDR in each group $\left(\mathrm{Al}\right.$ vs. $\mathrm{CO}_{2} \mathrm{I}$ ) based on the type of colonoscope. However, a significant proportion of procedures $\left(11.6 \%\right.$ in $\mathrm{Al}$ and $34.2 \%$ with $\mathrm{CO}_{2} \mathrm{I}$ ) did not specify the type of colonoscope used, which in turn limits any potential inferences from these findings. While we recognize that differences in the type of colonoscope between the 2 groups may affect the interpretability of our findings, its impact on polyp or adenoma detection rate remains debatable based on the conflicting available literature [35-37]. The association between withdrawal time and SPDR found in this study must also be interpreted with caution as all colonoscopies, and not only negative screening colonoscopies, were included in the withdrawal time analysis. Furthermore, we recognize that the SPDR could have been affected by inter-observer variability among pathologists at our institution and the potential for histological misclassification. The concern for this heterogeneity in pathological as- 
sessment is to some extent mitigated by the fact that there were no HPs $>10 \mathrm{~mm}$ detected in our entire cohort which may have been misclassified as SSAs/TSAs. In addition, we included all endoscopists who performed screening colonoscopies during the study period in order to limit selection bias. Consequently, there was significant variation in the number of procedures performed by each endoscopist thereby limiting our ability to evaluate individual performance characteristics and compare them among all endoscopists. We also acknowledge that, in recent years, there has been a heightened awareness of sessile serrated polyps in the endoscopy community and this could possibly have contributed to a higher SPDR in our cohort of patients undergoing colonoscopy more recently with $\mathrm{CO}_{2} \mathrm{I}$. Nonetheless, subgroup analysis (evaluating SPDR in each group in 6month periods) did not reveal an incremental SPDR with later time periods to suggest that higher SPDR with $\mathrm{CO}_{2}$ I was necessarily due to increased pathologist awareness of this diagnosis. Finally, while the adequacy of bowel cleansing has been linked to ADR, the impact of quality of the bowel preparation was not a factor for SPDR in our study (OR: 0.70; $95 \% \mathrm{Cl}: 0.35-1.42 ; P=$ 0.32 ). This apparent discrepancy may be in part explained by the bowel cleansing grading used in this cohort (Aronchick scale), which was specifically designed and validated to compare the efficacy of purgatives rather than outcomes such as SPDR. Furthermore, we acknowledge that the effect of bowel preparation in SPDR cannot be conclusively determine in this retrospective study as actual patient adherence to a specific purgative regimen cannot be determined.

\section{Conclusion}

In conclusion, this study demonstrates that $\mathrm{CO}_{2} \mathrm{I}$ was associated with a higher SPDR when compared to AI. In light of its faster spontaneous absorption across the intestine and decreased association with post-procedural discomfort, we speculate that endoscopists may aspirate less $\mathrm{CO}_{2}$ as compared to room air during colonoscope withdrawal. This in turn may result in improved bowel distention facilitating the detection of precancerous lesions, particularly of flat serrated polyps. These findings suggest an additional reason to prefer use of $\mathrm{CO}_{2} \mathrm{I}$ over $\mathrm{Al}$ during colonoscopy. Both $\mathrm{BMI}$ and colonoscope withdrawal time were also shown to positively correlate with SPDR in this study, highlighting the importance of further research on modifying patient- and endoscopist-related factors that may ultimately reduce the risk of these precancerous lesions and CRC.

\section{Acknowledgements}

This work was partly supported by NIH grant 1UL1TR000064 from the National Center for Advancing Translational Sciences (Bethesda, MD).

\section{Competing interests}

None

\section{References}

[1] Zauber AG, Winawer SJ, O'Brien M] et al. Colonoscopic polypectomy and long-term prevention of colorectal-cancer deaths. N Engl J Med 2012; 366: 687-696

[2] Siegel R, Desantis C, Jemal A. Colorectal cancer statistics, 2014. CA Cancer J Clin 2014; 64: $104-117$

[3] Pohl H, Robertson DJ. Colorectal cancers detected after colonoscopy frequently result from missed lesions. Clin Gastroenterol Hepatol 2010; 8: 858-864

[4] Snover DC, Jass JR, Fenoglio-Preiser C et al. Serrated polyps of the large intestine: a morphologic and molecular review of an evolving concept. Am J Clin Pathol 2005; 124: 380 - 391

[5] Barret M, Chaussade S, Coriat R. Detection rate of proximal serrated lesions: A new quality indicator for colonoscopy? Dig Liver Dis 2015; 47: $441-442$

[6] Bettington M, Walker N, Clouston A et al. The serrated pathway to colorectal carcinoma: current concepts and challenges. Histopathology 2013; 62: 367-386

[7] Erichsen R, Baron JA, Hamilton-Dutoit S] et al. Increased risk of colorectal cancer development among patient with serrated polyps. Gastroenterology 2016; 4: 895-902

[8] Torlakovic E, Skovlund E, Snover DC et al. Morophologic reappraisal of serrated colorectal polyps. Am J Surg Pathol 2003; 27: 65-81

[9] Okamoto K, Kitamura S, Kimura T et al. Clinicopathological characteristics of serrated polyps as precursors to colorectal cancer: current status and management. J Gastroenterol Hepatol 2017; 32: 02358 367

[10] Rex DK, Ahnen DJ, Baron JA et al. Serrated lesions of the colorectum: review and recommendations from an expert panel. Am J Gastroenterol 2012; 107: 1315-1329; quiz 1314, 1330

[11] Bressler B, Paszat LF, Chen Z et al. Rates of new or missed colorectal cancers after colonoscopy and their risk factors: a population-based analysis. Gastroenterology 2007; 132: $96-102$

[12] Arain MA, Sawhney M, Sheikh S et al. CIMP status of interval colon cancers: another piece to the puzzle. Am J Gastroenterol 2010; 105 : $1189-1195$

[13] Leggett B, Whitehall V. Role of the serrated pathway in colorectal cancer pathogenesis. Gastroenterology 2010; 138: 2088-2100

[14] Kahi CJ, Hewett DG, Norton DL et al. Prevalence and variable detection of proximal colon serrated polyps during screening colonoscopy. Clin Gastroenterol Hepatol 2011; 9: 42-46

[15] Hetzel JT, Huang CS, Coukos JA et al. Variation in the detection of serrated polyps in an average risk colorectal cancer screening cohort. Am J Gastroenterol 2010; 105: 2656-2664

[16] De Wijkerslooth TR, Stoop EM, Bossuyt PM et al. Differences in proximal serrated polyp detection among endoscopists are associated with variability in withdrawal time. Gastrointest Endosc 2013; 77: 617623

[17] Liang J, Kalady MF, Appau K et al. Serrated polyp detection rate during screening colonoscopy. Colorectal Dis 2012; 14: $1323-1327$

[18] Wu J, Hu B. The role of carbon dioxide insufflation in colonoscopy: a systematic review and meta-analysis. Endoscopy 2012; 44: 128-136

[19] Ferlitsch M, Moss A, Hassan C et al. Colorectal polypectomy and endoscopic mucosal resection (EMR): European Society of Gastrointestinal Endoscopy (ESGE) Clinical Guideline. Endoscopy 2017; 49: $270-297$

[20] Bassan MS, Holt B, Moss A et al. Carbon dioxide insufflation reduces number of postprocedure admissions after endoscopic resection of large colonic lesions: a prospective cohort study. Gastrointest Endosc 2013; 77: $90-95$ 
[21] Aronchick CA, Lipshutz WH, Wright SH et al. A novel tableted purgative for colonoscopic preparation: efficacy and safety comparison with Colyte and Fleet Phospho-Soda. Gastrointest Endosc 2000; 52: $346-352$

[22] Schlemper RJ. The Vienna classification of gastrointestinal epithelial neoplasia. Gut 2000; 47: $251-255$

[23] Snover DC, Ahnen DJ, Burt RW et al. Serrated polyps of the colon and rectum and serrated polyposis. In: Bosman T, Carneiro F, Hruban R et al. eds. WHO classification of tumours of the digestive system. Lyon: World Health Organization; 2010: 160-165

[24] Cotton PB, Eisen GM, Aabakken L et al. A lexicon for endoscopic adverse events: report of an ASGE workshop. Gastrointest Endosc 2010; 71: $446-454$

[25] Yamano HO, Yoshikawa K, Kimura T et al. Carbon dioxide insufflation for colonoscopy: evaluation of gas volume, abdominal pain, examination time and transcutaneous partial $\mathrm{CO}_{2}$ pressure. J Gastroenterol 2010; 45: $1235-1240$

[26] Dellon ES, Hawk JS, Grim IS et al. The use of carbon dioxide for insufflation during $\mathrm{Gl}$ endoscopy: a systematic review. Gastrointest Endosc 2009; 69: 843-849

[27] Geyer M, Guller U, Beglinger C. Carbon dioxide insufflation in routine colonoscopy is safe and more comfortable: results of a randomized controlled double-blinded trial. Diagn Ther Endosc 2011; 2011: 378906

[28] Payne SR, Church TR, Wandell M et al. Endoscopic detection of proximal serrated lesions and pathologic identification of sessile serrated adenomas/polyps vary on the basis of center. Clin Gastroenterol Hepatol 2014; 12: 1119-1126
[29] Brandt LI, Boley S], Sammartano R. Carbon dioxide and room air insufflation of the colon. Effects on colonic blood flow and intraluminal pressure in the dog. Gastrointest Endosc 1986; 32: $324-329$

[30] Hussein AM. Carbon dioxide insufflation for more comfortable colonoscopy. Gastrointest Endosc 1984; 30: 68-70

[31] Butterly L, Robinson CM, Anderson JC et al. Serrated and adenomatous polyp detection increases with longer withdrawal time: Results from the New Hampshire Colonoscopy Registry. Am J Gastroenterol 2014; 109: 417-426

[32] Feakins RM. Obesity and metabolic syndrome: pathological effects on the gastrointestinal tract. Histopathology 2016; 68: 630-640

[33] Platz EA, Willett WC, Colditz GA et al. Proportion of colon cancer risk that might be preventable in a cohort of middle-aged US men. Cancer Causes Control 2000; 11: 579-588

[34] Bailie L, Loughrey MB, Coleman HG. Lifestyle risk factors for serrated colorectal polyps: a systematic review and meta-analysis. Gastroenterology 2016; 152: $92-104$

[35] Burke CA, Choure AG, Sanaka MR et al. A comparison of high-definition versus conventional colonoscopes for polyp detection. Dig Dis Sci 2010; 55: $1716-1720$

[36] Tribonias G, Theodoropoulou A, Konstantinidis K et al. Comparison of standard vs high-definition, wide-angle colonoscopy for polyp detection: a randomized controlled trial. Colorectal Dis 2010; Oct 12: e260-266

[37] East JE, Stavrindis M, Thomas-Gibson S et al. A comparative study of standard vs. high definition colonoscopy for adenoma and hyperplastic polyp detection with optimized withdrawal technique. Aliment Pharmacol Ther 2008; 28: 768 - 776 